\title{
Arizona professor files lawsuit after being fired for misconduct
}

[SAN DIEGO] The University of Arizona has for the first time fired a tenured professor for scientific misconduct, spurring both a lawsuit by the scientist and an Internet support campaign.

Marguerite M. B. Kay, who studies Alzheimer's disease and the effect of age on cells, had her contract terminated last month after an investigation found she had manipulated and misrepresented data in three published articles, while mismanaging a laboratory in a way that was "a formula for disaster".

Last week, Kay, 51, filed a lawsuit against the Arizona Board of Regents in the State Superior Court in Tucson to attempt to overturn the university's action.

In an interview, Kay insisted the allegations are "patently untrue", saying she was railroaded by a biased university administrator who sought to oust her at any cost. Arizona officials denied any impropriety, saying academic rules were strictly followed.

Kay said there were some "honest errors" and "a typographical error" in the papers. She said her laboratory staff had used poor research methods without her knowledge. But there was no intent to deceive, she added.

A website - "Witch Hunt at the University of Arizona" — has been set up to solicit

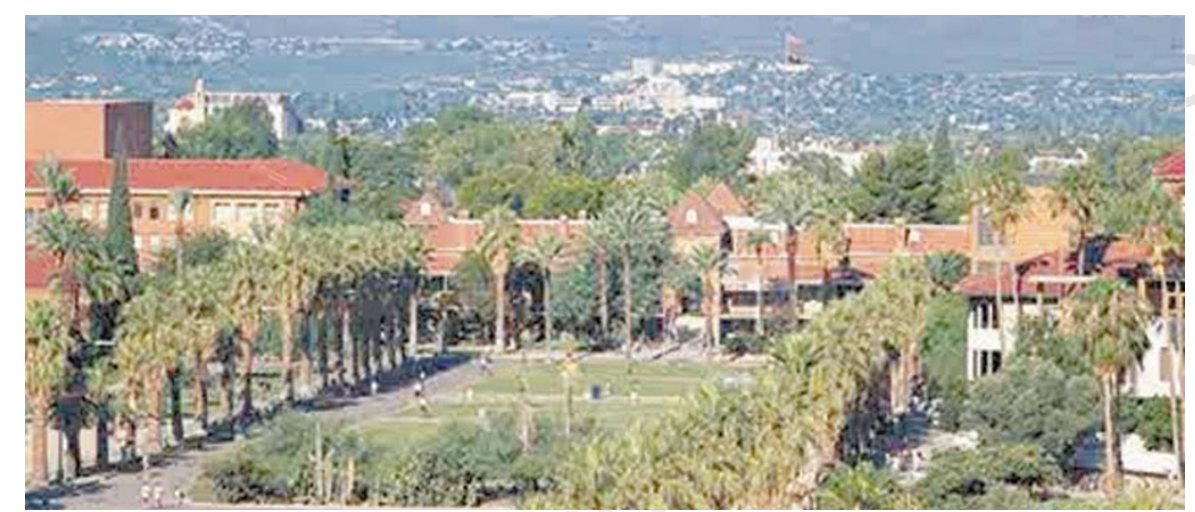

The University of Arizona: faces a court battle after firing a professor for misconduct.

funds for Kay's legal bills. The use of websites is coming into vogue as accused or concerned scientists seek new channels for redress. Kay denied knowing who set up the website, or how much money was received.

As Kay's research was funded by the National Institutes of Health, the federal Office of Research Integrity (ORI) is reviewing the university's action against Kay. After investigating, ORI will issue a report, which could bar Kay from receiving federal funds.

Last May, Arizona's Committee on Academic Freedom and Tenure issued its report

\section{Rethink urged on Framework programme}

[MUNICH] The European Commission should redesign the proposed research advisory system for its fifth Framework programme, which begins next year, according to the panel that previously advised it on research.

In its last piece of advice, the now defunct European Science and Technology Assembly (ESTA) said the new structure could lead to inefficient coordination of academic and industrial inputs, and confusion about the roles of its committees. In particular, ESTA objects to a plan to split industrialists and academics into separate advisory panels.

In June, the commission said it would set up a structure comprising 17 external advisory groups to oversee the Framework programme's 'key actions', and a twochamber body to advise on general European Union research policy (see Nature $393,502 ; 1998)$. One chamber will represent academics, the other the industrial community. The chambers will each have 25 members.

Members of ESTA, which comprised both academic and industrial researchers, were taken aback by the announcement, as they had been appointed only a few months earlier for a three-year period. Nobel laureate Carlo Rubbia resigned in protest.

Last month, other members were further offended to learn that ESTA was to be dissolved immediately, before the new structure has been put in place.

ESTA has given its full backing to the external advisory groups. But it believes the move to create separate chambers for academics and industrialists is retrograde, and will discourage coordination, particularly as the fifth Framework programme is designed to promote economically and socially relevant research.

It is also concerned that all 17 chairs of the external advisory groups will be members of the chambers, believing this could distract discussions from longer term perspectives by introducing more immediate operational concerns.

ESTA is asking for the two chambers to be merged as soon as possible, and for chairs of external advisory groups to be excluded from automatic membership of the combined chamber. on the allegations against Kay, noting an article in the Proceedings of the National Academy of Sciences (PNAS 93, 5600-5603; 1996) as a prime example of misconduct.

Kay and three co-authors wrote in the article that vitamin E supplements delayed the effect of ageing on the immune system and the brain. This study was the subject of national television news reports.

But the committee's report says the study falsely presented data on mouse immune cells, dropping, selecting or manipulating data points for the desired statistical results.

Insisting this was not true, Kay said there was no evidence to justify the committee's decision.

The report said Kay "hired untrained, mostly undergraduate students with minimal or no prior laboratory experience," and gave little supervision. Kay said people in her lab were correctly trained and supervised.

The lead author of the PNAS paper, Jeffrey E. Poulin, had just received his bachelor's degree in psychology, and two other authors were undergraduates; Kay was the last author. The academy member who sent the article to PNAS was an 87-year-old retired professor, whom Poulin had never met.

Poulin has disavowed the paper's results after learning in the investigation that Kay's research methods were flawed. PNAS editors say they were unaware of the article's deficiencies, which they will now review.

Poulin, 29, explained: "She [Kay] had a big name - like the Michael Jordan of research. I didn't know the way things were [normally] done. She had about 100 publications."

The investigation discovered that lab notebooks had disappeared and computer hard drives had been erased. But Poulin had kept computer copies of the raw data and notebook photocopies, which played a crucial role in the inquiry.

RexDalton 